\title{
Mean ST Deviation
}

National Cancer Institute

\section{Source}

National Cancer Institute. Mean ST Deviation. NCI Thesaurus. Code C62155.

The average (mean) deviation (distance from baseline, positive or negative, usually measured in $\mathrm{mm}$ ) of the ST segment, obtained from a set of measurements of the deviation of the ST segment. 